\title{
PRODUÇÃo E PARTIÇÃO DE MATÉRIA SECA E ABERTURA ESTOMÁTICA DO LIMOEIRO 'CRAVO' SUBMETIDO A ESTRESSE SALINO'
}

\author{
JAILSON LOPES CRUZ², CLAUDINÉIA REGINA PELACANI², WALTER DOS SANTOS SOARES FILHO², MANOEL \\ TEIXEIRA DE CASTRO NETO ${ }^{2}$, EUGÊNIO FERREIRA COELHO², ANTONIVALDA TOSTA DIAS ${ }^{4}$, RAFAEL AMOEDO \\ PAES $^{4}$
}

\begin{abstract}
RESUMO - O presente trabalho teve como objetivo avaliar a influência da salinidade sobre alguns parâmetros fisiológicos do limoeiro 'Cravo' (Citrus limonia Osbeck), principal porta-enxerto da citricultura baiana. Esses estudos são importantes, porque podem viabilizar a utilização de água de baixa qualidade para irrigação, com vistas a melhoria da produtividade dessa cultura. Sementes de limão 'Cravo' foram selecionadas quanto ao tamanho e colocadas para germinar em areia lavada. Três dias após a germinação as plantas foram transferidas para vasos plásticos contendo solução nutritiva. Após um período de adaptação de dez dias, os tratamentos salinos foram induzidos pela adição de quantidades de $\mathrm{NaCl}$ à solução de crescimento para a obtenção das concentrações finais de $0,20,40$ e $80 \mathrm{mM}$ de $\mathrm{NaCl}$. O experimento foi montado em um delineamento inteiramente casualizado, com quatro tratamentos (concentrações de $\mathrm{NaCl}$ ) e cinco repetições. Quarenta e dois dias após o início da imposição do estresse salino o experimento foi encerrado. Observou-se que a salinidade reduziu as produções das matérias secas totais, do caule e das raízes. $\mathrm{Nos}$ níveis intermediários de $\mathrm{NaCl}$ (20 e $40 \mathrm{mM}$ ) nem a área foliar e nem a matéria seca das folhas foram afetadas; esses caracteres foram afetados apenas no nível de $80 \mathrm{mM}$. O aumento dos níveis de salinidade determinou reduções na relação raiz:parte aérea das plantas, na condutância estomática, na transpiração e na temperatura foliar. Termos para indexação: Citrus, $\mathrm{NaCl}$, fisiologia, condutância estomática, transpiração.
\end{abstract}

\section{PRODUCTION AND PARTITIONING OF DRY MATTER AND STOMATAL CONDUCTANCE OF RANGPUR LEMON UNDER SALT STRESS}

\begin{abstract}
This research aimed to evaluate the influence of the salinity on some physiological parameters in Rangpur lime (Citrus limonia Osbeck), which is the principal citrus rootstock in Bahia. The importance of this study is based on the possibility of using water of low quality for irrigation, which is a production constraint for citrus crop. Rangpur lime seeds were selected by size and sowed in washed sand. Three days after the germination, the seedlings were transferred to plastic pots containing nutrient solution. After ten days, the saline treatments were applied by addition of $\mathrm{NaCl}$ to the growth solution in each pot, reaching the final concentrations of $0,20,40$ and $80 \mathrm{mM}$ of $\mathrm{NaCl}$. The completely randomized experiment had four treatments ( $\mathrm{NaCl}$ concentration) and five replications. Forty two days after the beginning of the saline stress the experiment was concluded. The salinity decreased total dry matter production of the stem and roots. In the intermediate levels of $\mathrm{NaCl}(20$ and $40 \mathrm{mM})$, neither the leaf area nor the leaf dry matter were affected; those characters were only affected in the level of $80 \mathrm{mM}$. The increase of the salinity levels caused reduction in the root:canopy ratio, in the stomatal conductance, in the transpiration and in the leaf temperature.
\end{abstract}

Index terms: Citrus, $\mathrm{NaCl}$, physiology, stomatal conductance, transpiration.

Altas concentrações de sais no solo têm sido um dos fatores que mais têm concorrido para a redução do crescimento e produtividade das culturas. Vale ressaltar que parte significativa desse problema ocorre em regiões onde a deficiência hídrica é acentuada e os solos são pouco profundos. Os prejuízos causados pela salinidade podem ser seriamente agravados pelo manejo inadequado da irrigação e pela drenagem insuficiente.

No Nordeste brasileiro, a expressão sócioeconômica da citricultura é incontestável. No entanto, a produtividade é baixa, devido, principalmente, ao déficit hídrico que ocorre, de modo mais acentuado, nos meses mais quentes do ano, de novembro a fevereiro. Assim, para que essa cultura alcance maiores níveis de produtividade, o emprego de irrigações suplementares constitui uma prática importante. Porém, um problema que se tem verificado nessa região é que a qualidade da água dos poços, açudes e rios nem sempre é adequada ao crescimento normal das plantas cítricas, em razão, principalmente, da relativamente alta concentração de sais. A redução no crescimento em resposta ao aumento da salinidade do meio de cultivo pode ser atribuída a um efeito direto dos íons $\mathrm{Na}^{+}$e $\mathrm{Cl}^{-}$sobre processos fisiológicos importantes da planta (efeito tóxico), e a um efeito indireto, devido à redução do potencial osmótico da solução de crescimento, a qual pode induzir condições de estresse hídrico. Em algumas situações a salinidade pode determinar reduções na condutância estomática (Sultana et. al., 1999) e na atividade fotossintética (García-Legaz et al., 1993 e Bañuls et al., 1997). A habilidade para minimizar o efeito negativo da salinidade está na depen- dência do genótipo utilizado (Lacerda, 2000).

Uma prática, que pode viabilizar o uso de água de baixa qualidade e de solos salinos, é a utilização de espécies/variedades que apresentem boa tolerância a esse fator abiótico. Nesse aspecto, variabilidade genética na tolerância à salinidade tem sido observada não apenas entre diferentes espécies, mas também entre diferentes genótipos de uma mesma espécie (Mass \& Hoffman, 1977). O desenvolvimento de cultivares mais tolerantes à salinidade, via programas de melhoramento genético, entretanto, exige que se desenvolvam estudos para se avaliar o efeito da salinidade sobre aspectos da fisiologia da planta, visando identificar processos que possam ser responsáveis por eventuais mecanismos de tolerância. Esses estudos são particularmente importantes para os citros, considerados bastante sensíveis à salinidade (Mass \& Hoffman, 1977) e alguns trabalhos desenvolvidos com essa cultura têm apresentado conclusões divergentes (Maas, 1993).

Assim, o presente trabalho teve como objetivo avaliar a influência da salinidade sobre alguns parâmetros fisiológicos do limoeiro 'Cravo' (Citrus limonia Osbeck), principal porta-enxerto da citricultura brasileira.

Sementes de limão 'Cravo' foram selecionadas, uniformizadas quanto ao tamanho e forma e, posteriormente, tratadas com Thiram ( $4 \mathrm{~g} \mathrm{~kg}^{-1}$ de sementes). Para a germinação utilizou-se caixas de isopor com células de $250 \mathrm{~cm}^{3}$. Dez dias após a germinação as plantas foram transferidas para vasos plásticos contendo solução de crescimento modificada, conforme Hoagland, com metade da força iônica original.

${ }^{1}$ (Trabalho 011/2003). Recebido 31/01/2003. Aceito para publicação: 11/09/2003.

${ }^{2}$ Embrapa Mandioca e Fruticultura, Cx. Postal 007 - CEP 44380-000, Cruz das Almas, BA, Brasil; e-mail jailson@cnpmf.embrapa.br.

${ }^{3}$ Universidade Estadual de Feira de Santana - Rod. BR 116, CEP 44031-460, Feira de Santana, BA, Brasil; e-mail pelacani@uefs.br.

${ }^{4}$ Estudante de graduação - Escola de Agronomia da UFBa, Cx. Postal 082, CEP 44380-000, Cruz das Almas, BA, Brasil. 
$\mathrm{O}$ arejamento da solução foi contínuo e o pH ajustado diariamente para um valor entre 6,0 e 6,5. Após um período de adaptação de dez dias, os tratamentos salinos foram induzidos pela adição de quantidades de $\mathrm{NaCl}$ à solução de crescimento para a obtenção das concentrações finais de $0,20,40$ e $80 \mathrm{mM}$ de $\mathrm{NaCl}$. A imposição do estresse salino foi gradual e de $20 \mathrm{mM}$ a cada 24 horas. As plantas foram cultivadas em condições de casa de vegetação. O experimento foi montado em um delineamento inteiramente casualizado, com quatro tratamentos (concentrações de $\mathrm{NaCl}$ ) e cinco repetições, sendo cada planta considerada como uma parcela.

Quarenta e dois dias após o início da imposição do estresse salino o experimento foi encerrado e as seguintes variáveis avaliadas: número de folhas, comprimento da raiz principal, área foliar (com um integrador de área marca Delta T, mod. MK2.), massas seca do caule, folhas e raízes (após secagem a $75^{\circ} \mathrm{C}$, por 72 horas). Com esses dados estimou-se a relação raiz/parte aérea e a massa foliar específica. A avaliação da condutância estomática, da temperatura e transpiração foliar realizou-se no horário das $10 \mathrm{~h}$, com um porômetro de difusão LI-1600C.

A análise estatística foi realizada mediante ajustes das equações de regressão. Optou-se pelo modelo que apresentou maior coeficiente de determinação, maior significância dos coeficientes e fosse melhor explicável do ponto de vista biológico. A análise foi feita utilizando-se do programa computacional SISVAR - Sistema de Análise de Variância para Dados Balanceados - desenvolvido por Ferreira (2000).

Com exceção do tratamento controle $(0 \mathrm{mM}$ de $\mathrm{NaCl})$, todos os outros apresentaram, em diferentes graus, sintomas de toxidez, que se caracterizaram pelo aparecimento de clorose e queima das bordas das folhas mais velhas (Figura 1), devido, provavelmente, a um maior acúmulo dos íons $\mathrm{Na}^{+}$e Cl , nesses tecidos (Storey \& Walker, 1998).
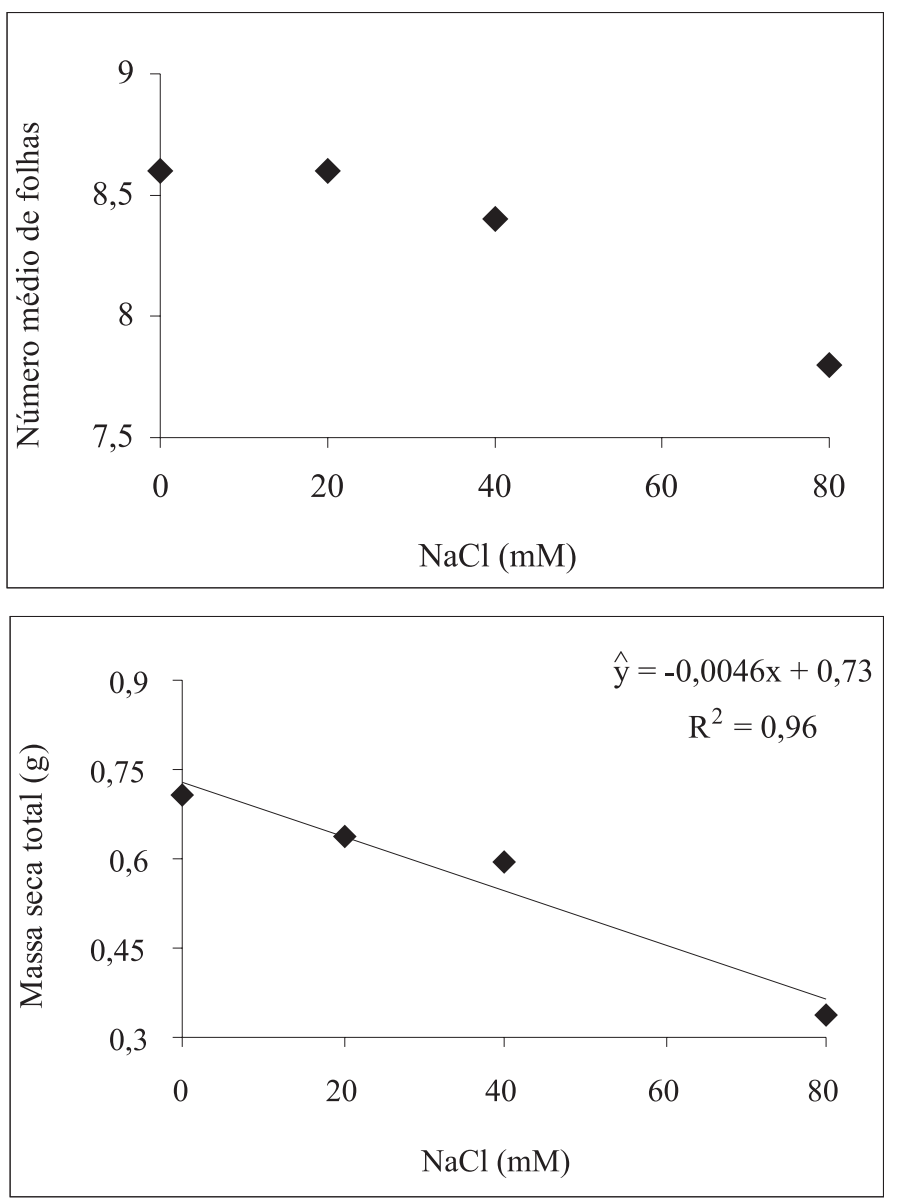

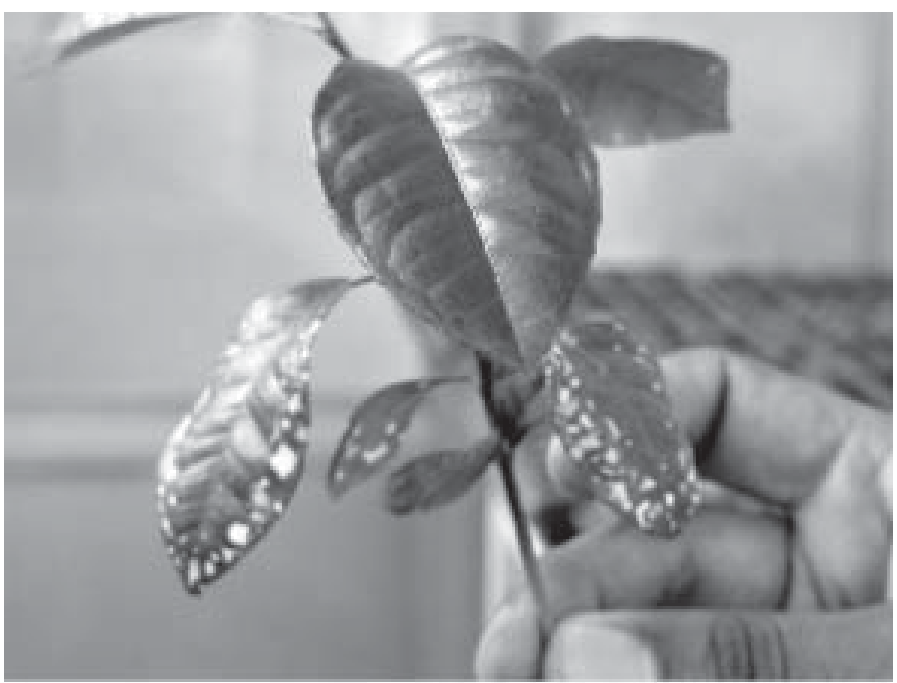

FIGURA 1 - Visualização do efeito da toxidez do $\mathrm{NaCl}(80 \mathrm{mM})$ nas folhas mais velhas do limoeiro 'Cravo'

Nas plantas cultivadas sob $80 \mathrm{mM}$, os sintomas foram mais severos e apareceram por volta dos vintes dias após a aplicação dos tratamentos salinos. Para as plantas do tratamento $20 \mathrm{mM}$, os sintomas foram leves e apenas começaram a ocorrer no final do experimento. A capacidade das plantas de limoeiro 'Cravo' em manter os íons $\mathrm{Na}^{+}$e $\mathrm{Cl}^{-}$ compartimentalizados nas folhas mais velhas pode ser um mecanismo adaptativo para proteger os ápices foliares e as folhas fisiologicamente mais ativas. Essa proposição é reforçada pelo fato de que o número de folhas não foi afetado pela salinidade (Figura 2). Além disso, a área foliar
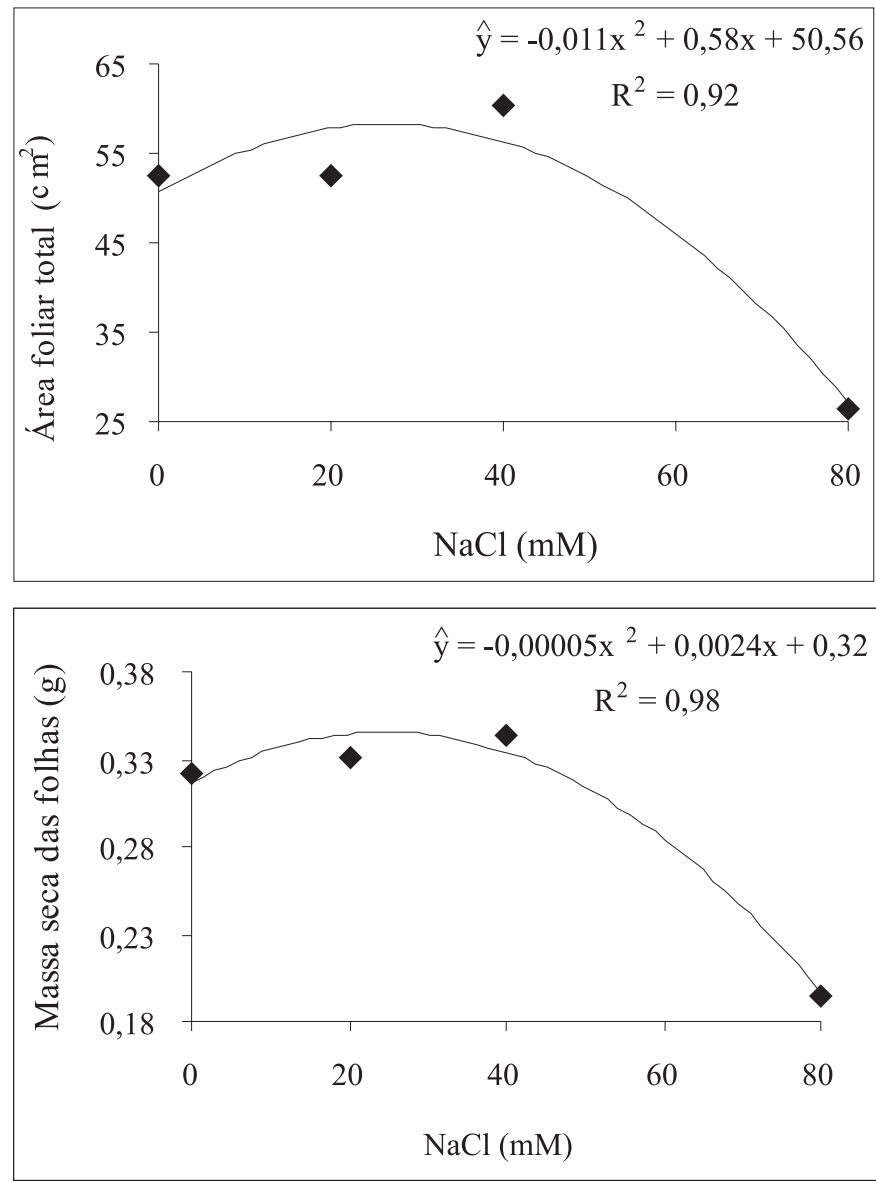

FIGURA 2 - Efeito da concentração de $\mathrm{NaCl}$ sobre o número de folhas, área foliar total, massa seca total e massa seca das folhas de limoeiros 'Cravo', cultivados por 42 dias em solução nutritiva. Valores são média de 5 plantas. 

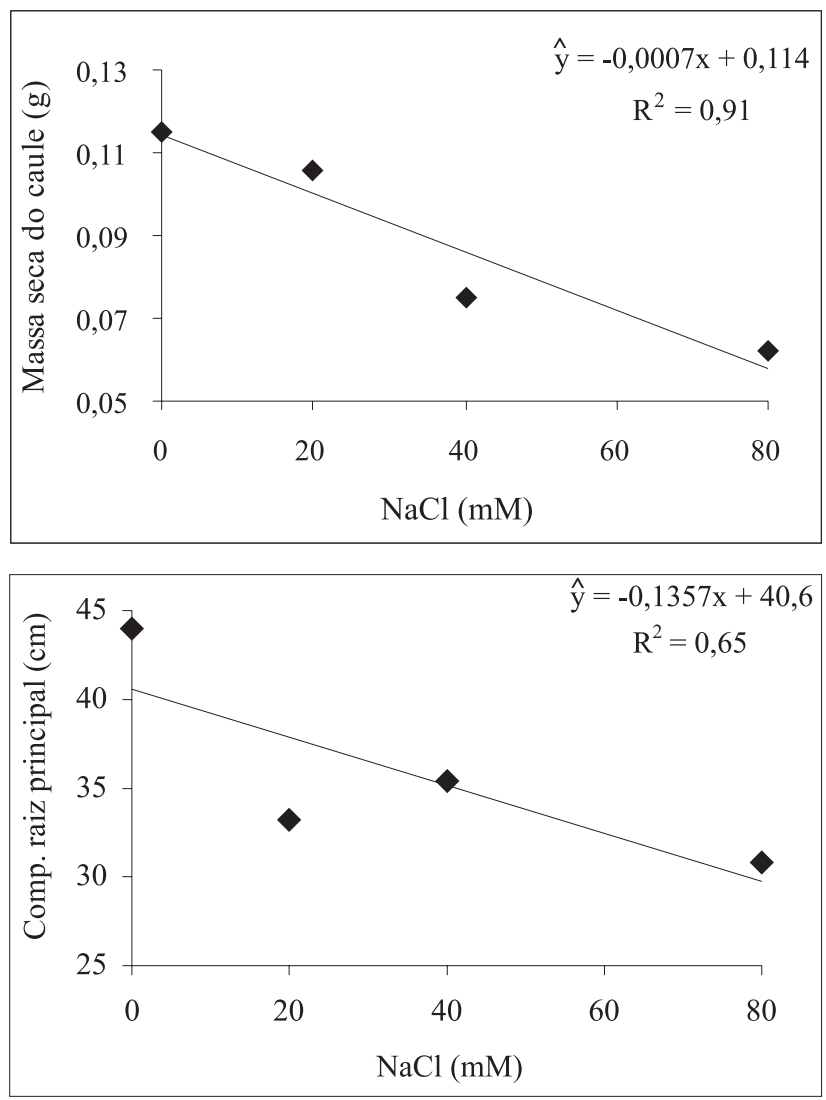
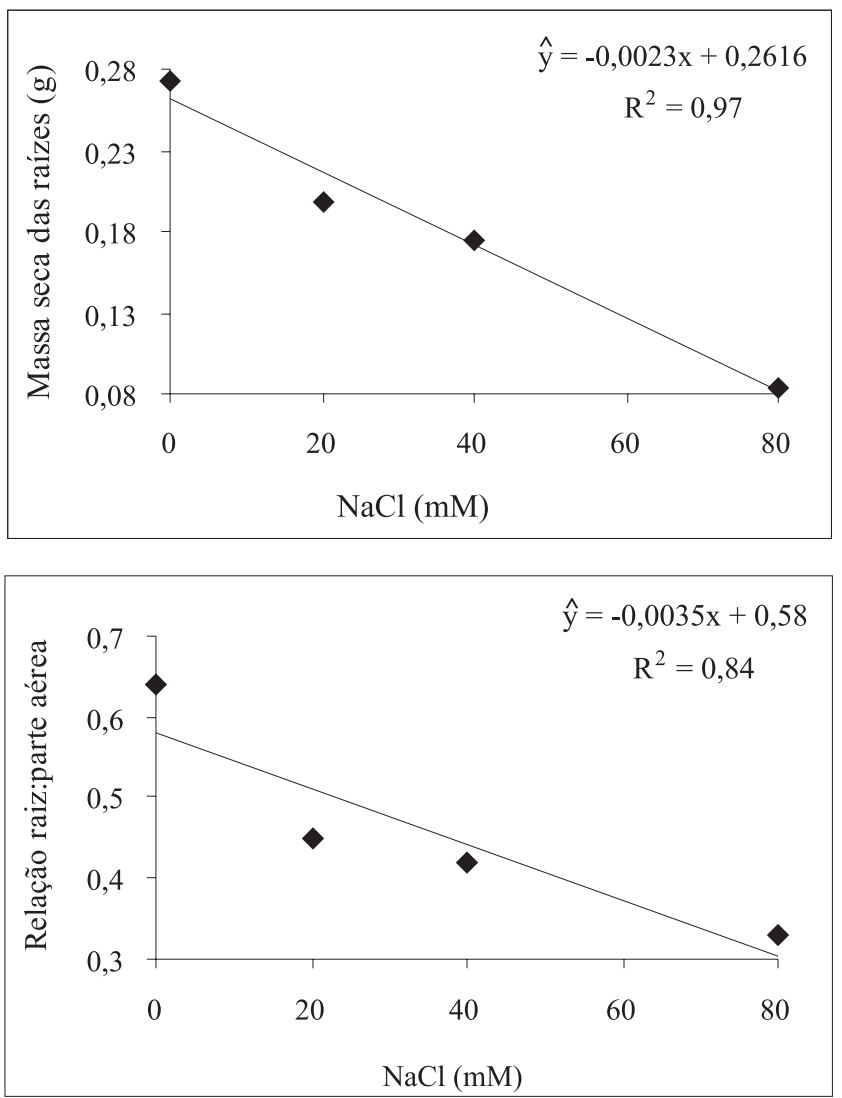

FIGURA 3 - Efeito da concentração de $\mathrm{NaCl}$ sobre a massa seca do caule, massa seca das raízes, comprimento da raiz principal e da relação raiz:parte aérea de limoeiros 'Cravo', cultivados por 42 dias em solução nutritiva. Valores são média de 5 plantas.

não sofreu redução devido à imposição de níveis intermediários de $\mathrm{NaCl}$ (20 e $40 \mathrm{mM}$ ), sendo apenas afetada pelo nível de $80 \mathrm{mM}$ (Figura 2). A significativa redução da área foliar das plantas cultivadas sob estresse severo de $\mathrm{NaCl}$ pode ter sido conseqüência da interferência negativa do tratamento salino sobre a divisão e/ou expansão celular. A análise da matéria seca total revelou que esse caráter foi negativamente associado aos níveis de $\mathrm{NaCl}$ no meio de cultivo, evidenciando que a redução no acúmulo de matéria seca é um dos principais efeitos negativos do estresse salino.

A análise do desmembramento das diferentes partes da planta evidenciou que a massa seca das folhas (Figura 2) não foi significativamente afetada pelos níveis intermediários $(20$ e $40 \mathrm{mM})$ de $\mathrm{NaCl}$. Assim, a menor massa seca total das plantas cultivadas sob condições de salinidade deveu-se ao menor acúmulo de matéria seca no caule e nas raízes (Figura 3), indicando que, nessas condições, as folhas são menos afetadas. Além do acúmulo de matéria seca, o estresse salino reduziu o comprimento da raiz principal (Figura 3 ) e, conseqüentemente, os pontos de aparecimento das raízes secundárias.

A relação raiz/parte aérea das plantas foi negativamente relacionada com os níveis de salinidade (Figura 3), evidenciando ter havido alteração no particionamento da massa seca em favor das folhas e não das raízes. A importância da relação raiz/parte aérea das plantas cultivadas em meio salino tem sido motivo de controvérsias. Um maior crescimento radicular pode levar à exploração de um volume maior do solo, favorecendo a absorção de água e de elementos essenciais, sendo particularmente importante em solos que apresentam limitada capacidade de fornecimento de nutrientes (Marschner, 1995), podendo beneficiar o crescimento das plantas. No entanto, um maior crescimento radicular, sob condições de salinidade, também pode levar a uma maior absorção de íons $\mathrm{Na}^{+} \mathrm{e} \mathrm{Cl}$, em níveis tóxicos, e o seu conseqüente carregamento para a parte aérea, prejudicando o crescimento da planta como um todo (Lacerda, 2000). Aparentemente, o menor crescimento do sistema radicular das plantas estressadas do limoeiro 'Cravo', observada no presente estudo, esteve relacionado com a retenção de altas concentrações de $\mathrm{Na}^{+}$e $\mathrm{Cl}^{-}$nessa parte das plantas, conforme indicação de Maas (1993). Como anteriormen- te comentado, esse pode ser um mecanismo para a proteção dos ápices foliares e a manutenção do aparecimento de novas folhas.

Em relação à massa foliar específica, é possível verificar que o tratamento salino tendeu a aumentar a expressão desse caráter, principalmente quando se observa o valor obtido na concentração de $80 \mathrm{mM}$ de $\mathrm{NaCl}$ (Figura 4), tratamento em que o crescimento da planta foi mais afetado (Figura 2). Para alguns autores, quando a capacidade de crescimento da parte aérea e/ou das raízes é reduzida, os fotoassimilados disponíveis tendem a ser direcionados para a formação de fibras e novas paredes celulares, levando ao aumento da massa foliar específica (Brown \& Byrd, 1997).

Os resultados das avaliações foliares de condutância estomática, temperatura e transpiração, também estão apresentados na Figura 4. A relação entre os níveis de salinidade aplicados e a condutância estomática foi linear, sendo o maior valor obtido pelas plantas controle. A menor condutância foliar obtida pelas plantas sob estresse salino provavelmente está relacionada ao estresse hídrico a que essas plantas estão sujeitas (Sultana et al., 1999), devido, principalmente à redução da condutividade hidráulica das raízes (Syvertsen \& Yelenosky, 1988). Vale ressaltar que o fechamento estomático, e a conseqüente redução do fluxo normal de $\mathrm{CO}_{2}$ em direção ao sítio de carboxilação, é um dos principais responsáveis pela redução da fotossíntese, em plantas cultivadas em condições de salinidade (Xu et al., 1994). Como conseqüência do fechamento estomático, as plantas cultivadas sob condições de salinidade apresentaram valores mais altos da temperatura foliar (Figura 4). Já a transpiração, apesar de manifestar a mesma tendência da condutância estomática, não apresentou significância estatística. Entretanto, a correlação entre a condutância e a transpiração foi alta e significativa (Figura 5), indicando que quando submetidas a condições salinas, plantas de limoeiro 'Cravo' tendem a fechar os estômatos, havendo, como conseqüência, redução na quantidade de água transpirada, a qual pode contribuir para redução na absorção e carregamento de ions $\mathrm{Na}^{+} \mathrm{e} \mathrm{Cl}^{-}$para o interior das plantas.

Com base nos resultados obtidos, pode-se concluir que: (i) a salinidade reduz as produções das matérias secas totais, do caule e das 

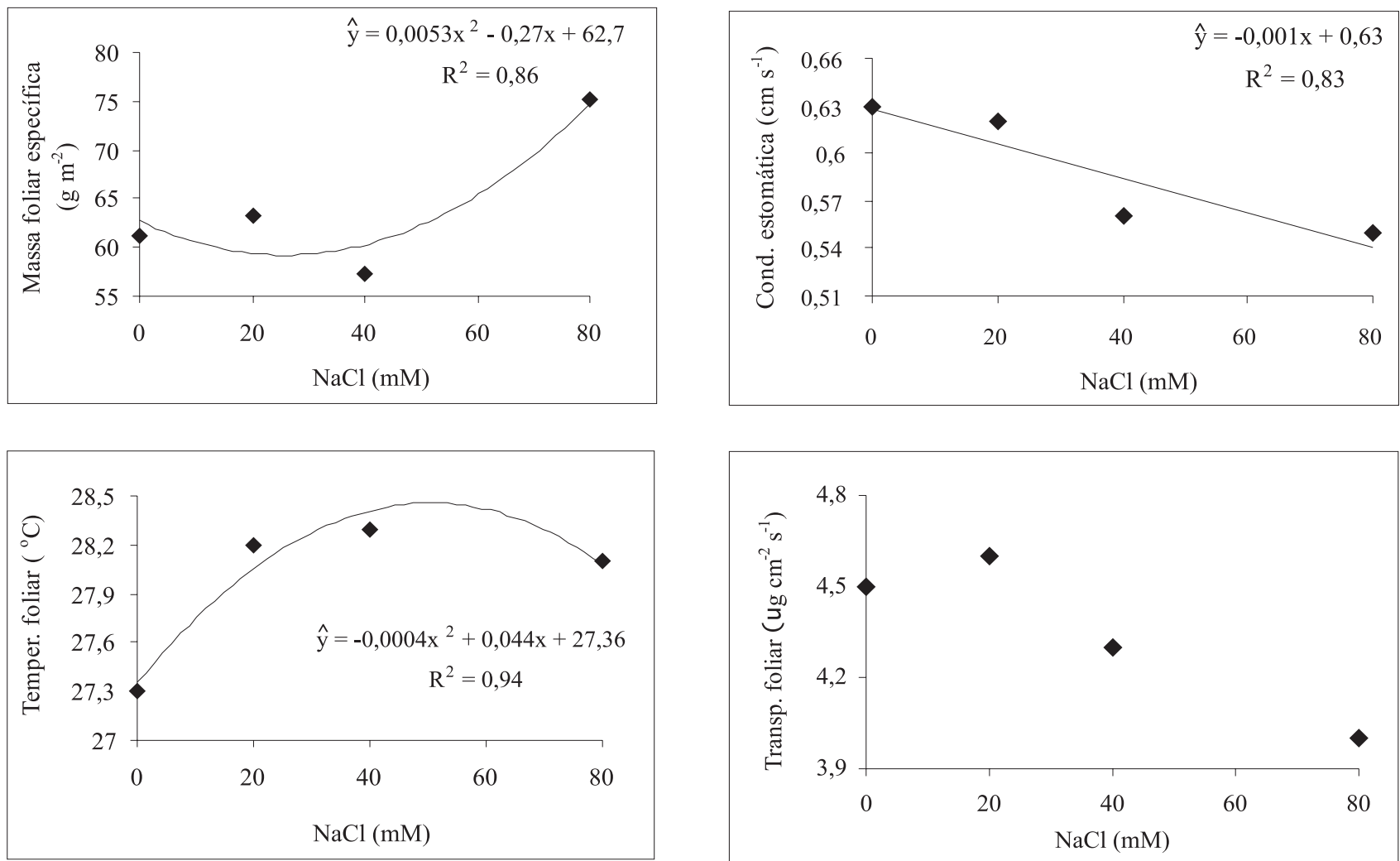

FIGURA 4 - Efeito da concentração de $\mathrm{NaCl}$ sobre a massa foliar específica, condutância estomática, temperatura e transpiração das folhas de limoeiros 'Cravo', cultivados por 42 dias em solução nutritiva. Valores são média de 5 plantas.

raízes; (ii) nos níveis intermediários de $\mathrm{NaCl}$ (20 e 40 mM) nem a área foliar e nem a matéria seca das folhas são afetadas. Esses caracteres são afetadas apenas no nível de $80 \mathrm{mM}$; (iii) o aumento dos níveis de salinidade determina redução na relação raiz/parte aérea das plantas e (iv) a salinidade reduz a condutância estomática e a temperatura foliar.

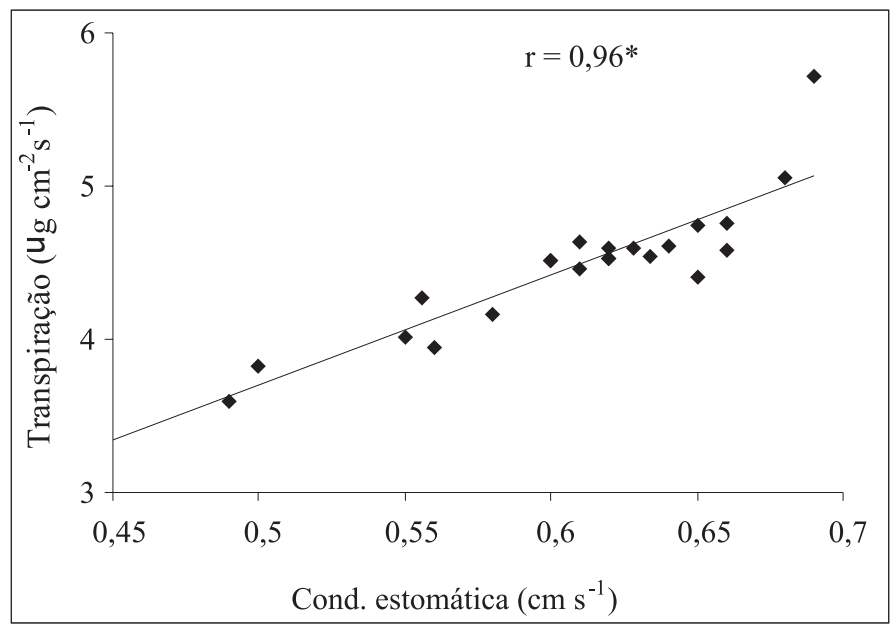

FIGURA 5 - Relação entre a condutância estomática e a transpiração de folhas de limoeiro 'cravo' $(\mathrm{n}=20)$, cultivadas por 42 dias em solução nutritiva contendo quatro concentrações de $\mathrm{NaCl}$. * Significativo em nível de 5\%.

\section{REFERÊNCIASBIBLIOGRÁFICAS}

BAÑULS, J.; SERNA, M.D.; LEGAZ, M.; PRIMO-MILLO, E. Growth and gas exchange parameters of Citrus plants stressed with different salts. Journal of Plant Physiology, Stuttgart, v.150, p.194_199, 1997.

BROWN, R.H.; BYRD, G.T. Relationships between specific leaf weight and mineral concentration among genotypes. Field Crops Research, Amsterdam, v. 54, p.19-28, 1997.

FERREIRA, D.F. Análises estatísticas por meio do Sisvar para Windows versão 4.0. In: REUNIÃO ANUALDA REGIÃO BRASILEIRADA SOCIEDADE INTERNACIONAL DE BIOMETRIA, 45., 2000, São Carlos, SP. p.255-258.

GARCÍA-LEGAZ, M.F.; ORTIZ, J.M.; GARCÍA-LIDON, A.G.; CERDÁ, A. Effect of salinity on growth, ion content and $\mathrm{CO}_{2}$ assimilation rate in lemon varieties on different rootstocks. Physiologia Plantarum, Copenhague, v.89, p.427_432, 1993.

LACERDA, C.F. Crescimento e acúmulo de solutos orgânicos e inorgânicos em dois genótipos de sorgo forrageiros submetidos a estresse salino. 2000. 163 f. Tese (Doutorado Fisiologia Vegetal) Universidade Federal de Viçosa, Viçosa, 2000.

MAAS, E.V. Salinity and citriculture. Tree Physiology, Victoria, v.12, p.195-216, 1993.

MAAS, E.V.; HOFFMAN, G.H. Crop salt tolerance - Current assessment. Journal of the Irrigation and Drainage Division, American Society of Civil Engineers, Reston, v.103, p.115-134, 1977.

MARSCHNER, H. Mineral nutrition of higher plants. 2.ed. London: London Academic Press, 1995. 899p.

STOREY, R.; WALKER, R.R. Citrus and salinity. Scientia Horticulturae, Amsterdan, v. 78, p.39-81, 1998.

SULTANA, N.; IKEDA, T.; ITOH, R. Effect of $\mathrm{NaCl}$ salinity on photosynthesis and dry matter accumulation in developing rice grains. Environomental and Experimental Botany, Kidlington, v. 42, p.211220,1999

SYVERTSEN, J.P.; YELENOSKY, G. Salinity can enhance freeze tolerance of citrus rootstock seedlings by modifying growth, water relations, and mineral nutrition. Journal of the American Society for Horticultural Science, Alexandria, v.113, p.889_893, 1988.

XU, H.L.; GAUTHIER, L.; GOSSELIN, A. Photosynthetic responses of greenhouse tomato plants to high solution electrical conductivity and low soil water content. Journal of Horticultural Science, Ashford, v. 69, p.821_832, 1994. 